\title{
How Improving the Customer Experience Quality and Business Performance? A Case Study by Mystery Shopper Practices
}

\author{
Yung-Lung Lai ${ }^{1} \&$ Shih-Chieh Chang ${ }^{2}$ \\ ${ }^{1}$ Ph.D Program in Business, Feng Chia University, Taichung, Taiwan \\ ${ }^{2}$ Gerneral Manager, Formosa Chang Corp., Taiwan \\ Correspondence: Yung-Lung Lai, Ph.D Program in Business, Feng Chia University, 100, Wen-Hwa. Rd, \\ Taichung City 40724, Taiwan ROC. E-mail: shamus.lai@gmail.com
}

\author{
Received: August 28, 2013 \\ Accepted: October 22, 2013 \\ Online Published: November 7, 2013 \\ doi:10.5539/ijms.v5n6p52 \\ URL: http://dx.doi.org/10.5539/ijms.v5n6p52
}

\begin{abstract}
This study aims to improve the quality of the customers' experience of Chinese restaurants through the mystery shopper service, which will enhance customer satisfaction and repurchases as well as business performance. Thus, this study conducted case study on Formosa Chang Restaurant which the enterprise operation and management was ranked first in Taiwan by IMD2012 reports. The research found that the approach of using customers with unpleasant experiences as mystery shoppers could effectively resolve Chinese customers' reluctance to tell service providers about their personal experiences so that the companies could introduce valid methods in order to improve equality of customer experience across the board. This study filled the gap as China had no research on the quality of experience for restaurants' customers and provided a method for using mystery shoppers as a way to improve customer experience quality.
\end{abstract}

Keywords: customer experience quality, service quality, mystery shopper, business performance, Confucian culture, Chinese restaurants

\section{Introduction}

Most companies have agreed that improvements in customer experience quality can let customer place high value on the company's brand, which in turn will strengthen the enterprises' sustainable competitive advantages (Berry et al., 2002; Berry \& Carbone, 2007; Lemke et al., 2010; Teixeira et al., 2012). Although many managers have employed the method of customer experience quality to further create customer values, unfortunately, only a small part of their customers agreed with their actions (Johnston \& Kong, 2011). Apparently, there is a world of difference between the enterprise and the customer's recognition of customer experience. So far, there are not many outstanding empirical studies on customer experience in research circles and business in practice (Gentile et al., 2007; Maklan \& Klaus, 2011; Teixeira et al., 2012).

The research samples of studies related to the catering service in the past are mainly sourced from restaurants located in Europe and the US. However, culture can influence customers' thinking and perception (Wang \& Mattila, 2008). It was presented that the United States and Canada are obviously cultures of individualism, whereas China, Japan and Korea are relatively in collectivism cultures (Ma et al., 2011). Under the influence of Confucius culture, Chinese customers tended to be reluctant to tell service providers their inner feelings, which prevented service providers from understanding customers' feelings about their experiences at restaurant. As a result, there were a rather limited number of researches on the topic of customer experience of Chinese restaurants. In addition, the applicability of the research results, which were based on studies of western restaurants, to Chinese restaurants was unknown (Heung \& Ngai, 2008). This study attempted to contribute to fill the gap between the eastern and western researches through a more practical method - a case study using the mystery shopper as the research objects - to find the specific details about the Chinese customer experience and assist Chinese restaurants to improve their quality of customer experience and promote their business performance. The author expects the research results of this paper could contribute to elicit the enterprises' perceptions and customers' expectations in terms of customer experiences.

Thus, this study conducted case study on Formosa Chang Restaurant, which it started from the business model of a street vendor. This business had experienced three business innovations; introduction of TQM in 1999, passing 
the ISO 9001 verification in 2000 and starting an international operating policy, before finally transforming into an international chain restaurant. Formosa Chang became the largest fast-Chinese-food restaurant in Taiwan and the annual business volume increased by 300 times, from USD 100,000 in the first stage to USD 30 million in the fourth stage. The reasons for selecting the Formosa Chang restaurant chain include, firstly, according to 2012 IMD Word Competitiveness Yearbook issued by the International Institute for Management Development in May, 2012, the enterprise operation and management of Taiwanese companies are ranked first in the world for efficiency, which is the seal of approval for the competitiveness of Taiwanese private companies worldwide (http://www.imd.org). Secondly, the subject of this case study is the biggest Chinese fast food chain corporation in Taiwan.

\section{Literature Review and Conceptual Model}

\subsection{Customer Experience Quality Is Superior to Service Quality}

Customer experience quality is considered to be the outstanding or advantageous perception and judgment of customer experience (Lemke et al., 2010) in terms of measuring customer service quality. The discussion of service quality is concerted on customer satisfaction and the manipulation of a good service quality is enterprises' providing an outstanding service content to customers (Palmer, 2010). The two dimensions, customer experience and satisfaction are inextricably linked in terms of quality and quantity (Johnston, 1999). However, service quality and customer experience quality should be regarded from different positions and perspectives. The two concepts can be defined from two perspectives. Service quality is the evaluation of how to deliver a service (definition of delivering a service includes working process, operating training manual, etc.) under enterprise's' regulations. Service quality lays emphasis on the perspective of the enterprise's providing service to their customers. Meanwhile, customer experience quality is the judgment initiated by customers regarding to the service quality they have perceived. Different to their experiences and deemed benefits, it is the customers' requirements and expectations, reflecting the customers' recognition of the enterprise. Moreover, customer experience quality excels service quality in importance. For instance, as the content of service manipulation method is handed to service personnel through the company's human resource management and regulation system, the control over the level of service quality is supposed to be sufficient. However, it does not mean that the service provided in accordance with the company's regulation and human resource system is satisfactory to customers (Johnston \& Kong, 2011).

In literature, one method for evaluating the service quality was to place the emphasis on customer satisfaction, but this type of customer expectation is based on certain conditions. If a customer had a low or narrowed-defined service expectation, companies may have considered that the service quality they provided was good. Apparently, this method had certain drawbacks (Berry et al., 2002; Nunes \& Cespedes, 2003; Rowley, 1999). Most researches on service quality contained such a hypothesis: consistency exists between the influential factors of the service quality. This hypothesis, basically, ignored the consumer's opinion and emotion out of considerations (Palmer, 2010). Additionally, researches on service quality seldom touched on how to understand the formation of and continuous retention of consumers' expectation. This is a significant omission because it is an enterprise's attitude instead of the service provided during the consuming process that decides the consumer's intention to repurchase (Palmer, 2010). Customer experience quality has a stronger connection between customers and companies than that of product quality and service quality alone (Lemke et al., 2010). More direct experiences of consumers can be verified, based on customer behavior, to improve an enterprise's organizational management, forming a virtuous circle between customer satisfaction, companies and consumers. Customer repurchases are directly related to an enterprise's ability to gain profit. Therefore, customer experience quality is a more specific term for products and services. It includes customer loyalty and word of mouth communication related to customer experience. Customer experience quality is also a better tool to predict an enterprise's competitiveness (Maklan \& Klaus, 2011).

\subsection{A Mystery Shopper Can Provide More Qualified Information than Ordinary Customers}

More and more managers have come to realize that they have to deliver value to customers in the form of customer experience (Berry et al., 2002; Berry \& Carbone, 2007). However, to understand customer experience quality of Chinese restaurants is by no means an easy task. Due to the influence of the Confucian culture, Asian customers tend to express dissatisfaction less often, because they consider it is important to "save face", both for others and for themselves (Ma et al., 2011). Consequently, Chinese customers are less willing to tell service providers about their experiences. As a result, it is more difficult for service providers to access to their customers' experiences.

The mystery shopper service is a tool used to gather an in-depth understanding of potential customer opinions. It 
can add value to the investigation data of customer satisfaction, and lead to the improvement of a manager's communication in their enterprise. Mystery shoppers are mostly used to measure the service quality delivered to customers, as well for other purposes (Wiele et al., 2005). In the long term, it should be able to predict the service perceived by customers (Wilson, 2001). As mystery shoppers are well-trained and understand the process of service, they can find out the main problems. Therefore, the suitable experience clue expected by customers should be further extended. After all, mystery shoppers themselves are customers. Moreover, if mystery shoppers represent regular customers, they can offer more qualified information than the normal consumer (Finn \& Kayande, 1999).

\subsection{Framework of Conducting Mystery Shopper Activity in Chinese Restaurants}

Previously, limited attention has been given to customer experience quality in academic researches. Furthermore, most researches have focused on the operating tools and how to help design and assess customer experiences. However, these tools studied were not in agreement. They did not seem to support the research evidence which enterprises and practices considered to be necessary (Johnston \& Kong, 2011).

Johnston (2011) and his colleagues proposed 10 ways of measuring customer experience. Unfortunately, they did not discuss how to encourage customers to give suggestions to enterprises. In addition, the theme of how to improve customer experience quality was not fully explored. A more specific research on this topic was Lemke et al.'s (2010) conceptual model. However, it was a pity that Lemke et al.'s (2010) model lacked a combination of strategy concepts. This is because, from the perspective of a customer, customer experience quality can optimize an enterprise's recognized products and service quality in order to exceed the customers' expectations, which needs strategy management.

In addition, food is still the most important factor that influences customers' satisfaction with the Chinese restaurant experience (Ma et al., 2011). Improvements in food quality will influence customers' perceived value of foods and their recognition of a restaurant image. This will further enhance their behaviour intentions and purposes after achieving customer satisfaction, such as repeat purchases, word of mouth advertising and so on (Ryu et al., 2012). Therefore, managers should introduce creative strategies to improve their products and services (Simon \& Petnji Yaya, 2012). Furthermore, the relations between the strategies adopted and business performance will be the focus of researches in the future. As previously mentioned, customer experience should be directly connected with an enterprise's profitability (Maklan \& Klaus, 2011), which will be manifested in the overall performance of the business in the end. In conclusion, the evaluation of business performance should value the factor of whether mystery shopper activity can facilitate an enterprise's staff performance and product innovation (Margaret Erstad, 1998; Alan M. Wilson, 1998).

This study referred to Lemke et al.'s (2010) conceptual model. It took the mystery shopper, the managing strategy of experience quality, and business performance into consideration, and proposed a model for improving the experience quality and business performance of Chinese restaurants through mystery shopper activities, as shown in figure 1.

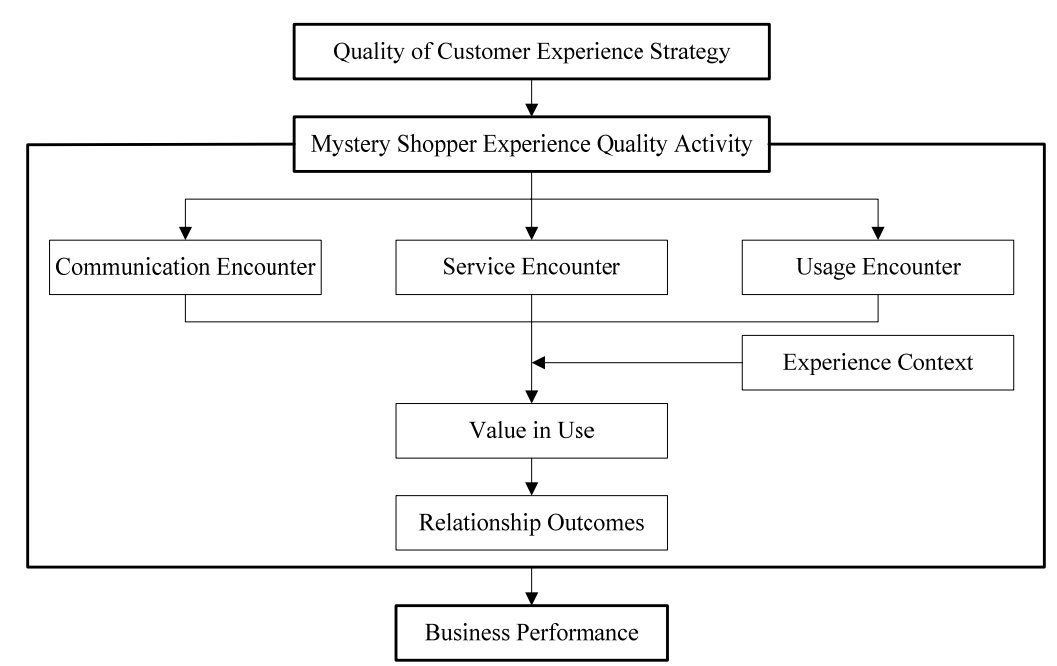

Figure 1. Conceptual model for improving customer experience quality through the mystery shopper Source: Lemke et al. (2010). 
According to Lemke et al. (2010), communication encounter refers to the definite, public, quick, positive and effective processing of a transaction between the entire enterprise and the customers. During a series of transactions, customers judge that the enterprise can sincerely maintain a positive relation between them. Service encounter can be understood as "value for money". Usage encounter consists of two closely-related categories: 1. relation with other customers; and 2. society representative impact. During the process of consumption, there is a category of customer experience, which will extend to other customer categories. Experience context refers to the expected experience about a market or products possibly formed by customers. This expected experience will influence the relations among value-in-use and the abovementioned three concepts. Palmer (2010) held that, for consumers, their all-round experience may take other non-controlled parts of an enterprise into consideration. For instance, providing a parking space may be the key experience factor that helps customers to decide to dine at a restaurant. Consequently, the managers of Chinese restaurants should pay close attention to the time when customers come to dine. It is quite important to provide the convenience of an easy location and a parking space for customers (Ma et al., 2011). Relationship outcomes refer to the customer experience quality that leads to the emotional promise of customers, which turns out to be the continuous use or consumption of customers. Finally, this will be reflected in business performance.

\section{Methodology}

Yin (2008) held that a case study is an attempt to find out why, how to realize and what decides the result. This study discussed the application of the mystery shopper to determine customer experience quality. It focused on "how", and attempted to provide an insight for the researching phenomena.

Thus, the data collection included interviews and secondary sources. Interviews lasted two to three hours, and the interview process was undertaken between June and August 2012. Interviewees included the enterprise president (1 interview), general managers (3 interviews) and managers of the quality control department (3 interviews). All interviews were conducted with the approval of the interviewees. Then, the audio files of the interview were converted into detailed written records. Secondary sources contained the reports from newspapers, feature stories in magazines, book chapters in enterprise monographs, videos and net news about the case-studied corporation. Mystery shoppers were named anonymously as A, B, C,... and $\mathrm{H}$.

\section{Analysis and Discussion}

\subsection{Background of the Enterprise}

Formosa Chang restaurant was chosen for the case study as it started from the business model of a street vendor. This business had experienced three business innovations; introduction of TQM in 1999, passing the ISO 9001 verification in 2000 and starting an international operating policy. Finally, transforming into an international chain restaurant, please refer to figure 2 .

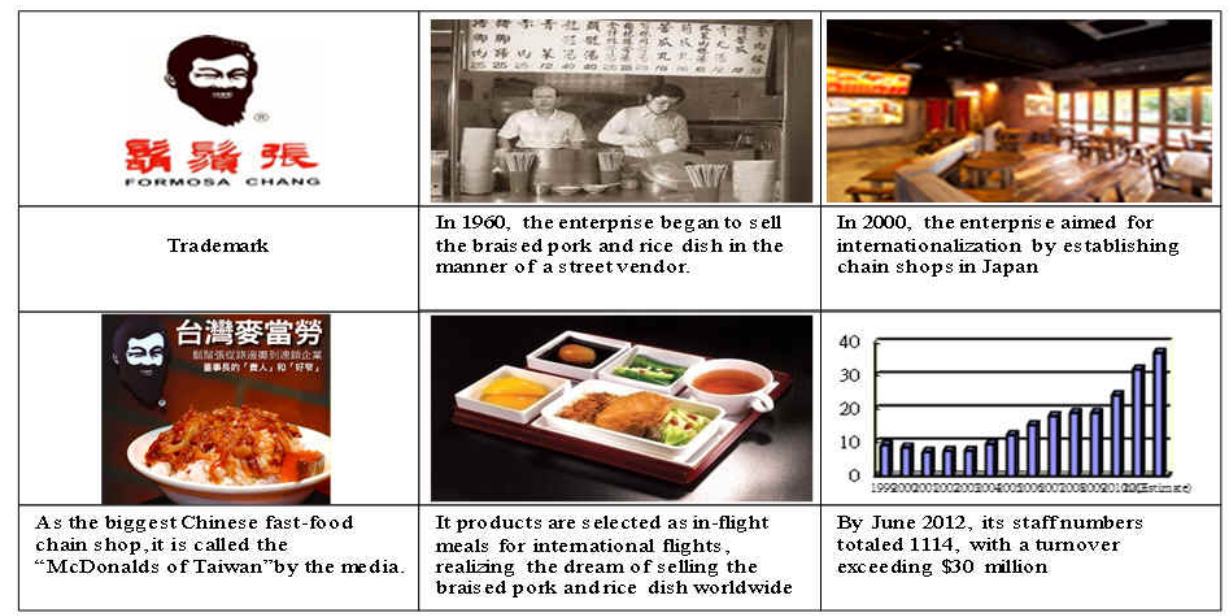

Figure 2. Background of Formosa Chang restaurant

\subsection{Quality of Customer Experience Strategy}

Many companies employ external mystery shoppers provided by professional enterprises or consultant 
companies. However, the disadvantages of external mystery shoppers are obvious: they cost more and are unfamiliar with the enterprise. The case-studied corporation introduced mystery shoppers in 2008. It implemented the plan of "changing complaining customers into mystery shoppers", inviting customers with complaints to be its mystery shoppers. In addition to solving the issue of customer complaints, customers can also re-experience the service quality. In this way, these customers felt respected and they actively gave suggestions on how to improve the quality of the experience, which delivered values to customer at the same time.

By June 2012, there were a total of 86 mystery shoppers distributed across the various departments of the corporation. They played the role of the corporation's eyes, monitoring the corporation and caring about corporate emotions. The corporation holds a "Mystery Shoppers Going Home" activity annually. In the "Symposium on Mystery Shoppers' Focuses", senior executives, including the corporation president and general managers, were in full participation.

This not only closed to the distance between customers and the corporation, but the mutual interaction of ideas and opinions also inspired new strategies for improvements in customer experience quality. The case study adopted the strategy, as shown in figure 3.

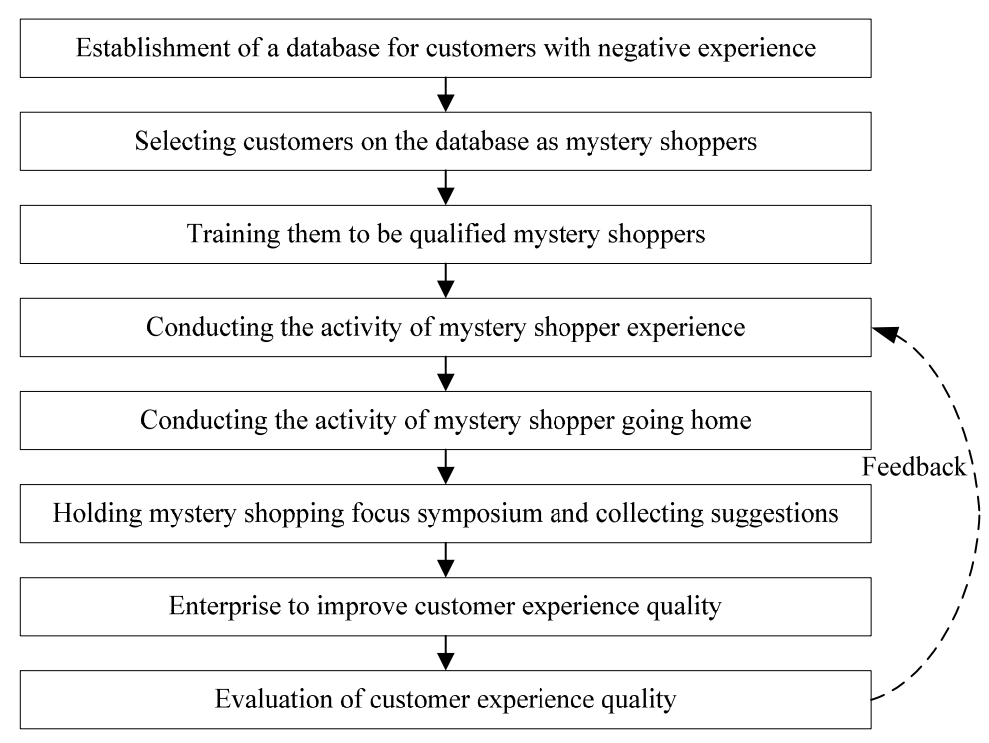

Figure 3. Formosa Chang quality of customer experience strategy

\subsection{Mystery Shopper Experience Quality Activity}

\subsubsection{Communication Encounter}

The case-studied corporation attached much importance to customers' suggestions, complaints and appeals. It accepted the examination of GSP (Good Service Practice) for its service quality and ISO annually. Furthermore, the corporation established a management system for mystery shoppers, delivering customers' opinions honestly and quickly to the related restaurants through the Internet, text message system and 0800 customer service line and putting it on record to trace any improvements to the situation.

The general manager said, "About 17,000 customers come to dine each day. When a customer complains that there is something wrong with our products, our corporation requires the problem to be handled within 30 minutes, and be resolved completely within 24 hours. Customer satisfaction after problem settlement has to exceed $80 \%$."

The development of 86 complaining customers into mystery shoppers indicated that both the corporation and customers had a sincere wish to maintain appropriate positive relationships and those they were willing to invest in these relationships. This had exceeded the scope of commonly mutual beneficial communication. Through the investigation of mystery shoppers and customer satisfaction, mystery shoppers' expectations for brand relations could be understood. Therefore, the corporation decided to launch a series of brand rejuvenation activities. It entrusted a professional brand consultancy enterprise with the task of combining the face logo with the fashion 
culture, producing different styles of creative T-shirts. This brought the brand to the 2008 Taiwan Rock Music Festival.

The corporation president said, "We can't tell whether brand rejuvenation is helpful, but I believe it will bring a new fashion."

Mystery shopper A: "A native brand of Taiwan suddenly becomes younger..."

Mystery shopper B: "Faddish Formosa Chang..."

Mystery shopper C: "Fashionable Formosa Chang's braised pork on rice..."

Table 1. The case-studied corporation's method of customer satisfaction investigation

\begin{tabular}{|c|c|c|}
\hline & Procedure & Operation \\
\hline 1 & Investigation frequency & Once in March and once in September, per year. \\
\hline 2 & Definition of target customers & Discrimination of main customers on the basis of population statistics. \\
\hline 3 & Designing the questionnaire & $\begin{array}{l}\text { Sorting out the key issues from customers' suggestions and structuring them into } \\
\text { a questionnaire. There are } 12 \text { indexes in total (1. Stable quality, } 2 \text {. Taste, } 3 \text {. Food } \\
\text { temperature, } 4 \text {. Politeness, } 5 \text {. Service speed, } 6 \text {. Checking out speed, } 7 \text {. Clean } \\
\text { environment, } 8 \text {. Lights and music, } 9 \text {. Clean toilets, } 10 \text {. Sense of value, } 11 \text {. } \\
\text { Serving staff appearance, } 12 \text {. Professional level of products) }\end{array}$ \\
\hline \multirow[t]{2}{*}{4} & Questionnaire reliability and validity control & $\begin{array}{l}\text { 1. Each time, } 6080 \text { questionnaires were issued, and the number of } \\
\text { questionnaires for each sample has to be ten times the number of question. } \\
\text { 2. For sampling } 50 \% \text { of the questionnaire was issued before the rush hour, } \\
50 \% \text { was after that time. Questionnaires were allocated to fixed tables to } \\
\text { avoid investigators issuing questionnaires by preference, which may cause } \\
\text { investigation bias. }\end{array}$ \\
\hline & & $\begin{array}{l}\text { 3. Under the questionnaire confidence level of } 95 \% \text {, sampling error did not } \\
\text { exceed } 3.5 \% \text {. }\end{array}$ \\
\hline 5 & Questionnaire analysis & $\begin{array}{l}\text { 1. Classification and encoding of questionnaires. } \\
\text { 2. Processing of missing value, reliability and validity by SPSS software. } \\
\text { 3. Reorganization and conclusion of open-ended questions by means of key } \\
\text { event skills. }\end{array}$ \\
\hline 6 & Final analysis report & Entering ISO quality management program. \\
\hline
\end{tabular}

According to the customer satisfaction investigation conducted in March 2011, the innovation result of the brand is shown in Table 1. Consumers aged from 20 to 29 accounted for $28 \%$ of the total customer number, increased by $40 \%$ than in September 2008, which was only $20 \%$. Brand rejuvenation also strengthened customer recognition. The young generation brought a positive influence to business performance.

\subsubsection{Service Encounter}

Mystery shoppers reported their dining experience to the relevant departments in real time as an improvement reference. A mystery shopper symposium was also held annually to collect suggestions on experience quality, such as products, services and sanitary conditions. Decision makers convened department managers to attend the symposium and make records. Taking the opportunity for quality examination, feedback information was developed to enhance customer loyalty.

The general manager said, "Formosa Chang has many important innovations, which have originated from the voice of mystery shoppers, such as product innovation and the improvement in hygienic conditions. By means of mystery shopper investigations, about two new products are presented for the public each month. As for hygienic conditions, mystery shoppers gave a lot of suggestions on the service environment and canteen washroom cleanliness at symposiums. These suggestions became the focus of improvement for the corporation. Most customers coming to the flagship shop at Ningxia Night Fair praise the fashionable design of the shop and the friendly service of the staff, which provides a pleasurable and relaxing environment for customers and makes them feel practical and enjoyable."

The above-mentioned service provider showed concern over mystery shoppers. During the symposiums, department managers convened to listen to the voice of the customer. Subsequently, practical improvements were carried out in service encounters to make customers feel valued, which formed a kind of guarantee and 
reliability for customers.

The corporation president said, "We adhere to the service principle of 'quick reception, ordering, serving and cleaning'. Staff must serve the first course within one minute after a customer finishes ordering. Quick service aims to save customers' dining and waiting time. Especially, the noon means a lot for office workers. Therefore, the average dining time for each table is only 15 minutes. It's the quickest-serving restaurant in the fast-food industry."

As far as service encounter is concerned, the case-studied corporation knows that the most important issue for customers is time. This concurs with what Lemke et al. (2010) held with this concept: that customers pay more attention to the time taken by service providers, and whether they can make use of customers' time effectively. For Internet encounters, an online service is provided around the clock all through the year, including weekends and holidays. Special staffs are in charge of these affairs to solve problems and meet customers' requirements, timely and satisfactorily.

Mystery shopper D: "Its course serving is speedy, but the soup is not hot enough. I left a complaint message on its website and received a phone call of apology from the restaurant's manager within 30 minutes. He insisted on giving me the money for the soup back in person and offering a free bowl of sweet soup, which made me felt flattered. I often go to dine in the restaurant and recommend my friends online to try Formosa Chang."

Mystery shopper D resorted to the Internet to make the service provider improve his experience quality, while the service provider's way of response stabilized the relationship between the two sides. This prompted the customer to conduct more word of mouth advertisements online. Grewal et al. (2009) supported this practice. They held that the improvement of experience at each encounter would lead to higher customer satisfaction, more frequent visits and more profit.

\subsubsection{Usage Encounter}

The case-studied corporation's headquarters is located at the Ningxia Night Market of Taipei. The corporation's president had organized restaurants with an average of 50 years of history to present 20 famous snacks of Taiwan, which was called the millennium feast (50 years of history $* 20$ restaurants $=1000$ years) and this attracted thousands of consumers from Hong Kong, Singapore, Malaysia and Japan. Its popularity was amazing: customers had to spend one month on a waiting list to make a reservation, which naturally formed a social cultural activity for international gourmet.

The corporation's president said, "As a matter of fact, the idea of holding the 'millennium feast' stemmed from the voice of a customer. This customer accepted my invitation to enjoy snacks at the Ningxia Night Market. We tried only three booths and felt full. He suggested that I serve the snacks on one table, which was agreed by several other snack bosses and I. Then, the idea of the 'millennium feast'was generated."

The idea of the millennium feast was proposed by a customer and was further supported by the case-studied corporation by organizing more service providers to take part. This created value for the restaurants. Meanwhile, because of the special nature of this feast, it was not only domestic consumers who joined in the experience; overseas consumers also came to enjoy the activity.

\subsubsection{Experience Context}

As a traditional Chinese food, braised pork on rice is sold everywhere you can see a Chinese restaurant in the street. It is a high-quality product with a good price. However, customers can enjoy a noble experience in the case-studied corporation.

Mystery shopper G: "Wow! You are so considerate! The braised pork on rice is served with so much dignity!"

According to customer $\mathrm{G}$, he had low expectation towards the product and its service before the experience. After personal participation, he had a pleasurable experience, which exceeded his original expectation.

Mystery shopper H: "Our families are regular customers of Formosa Chang. My son, a high school student, likes the big serving of braised pork on rice and the corn soup. I love the braised pork on rice and bitter melon and sparerib soup. I've been engaged in international trade for many years. Every time I have overseas customers, I will treat them in Formosa Chang. It's not only yummy, quick and clean, the staffs are also friendly. You'll feel respected here. Even my Japanese customers who had dined here gave a thumbs-up, saying ‘おい '(yummy)' and asking whether there was a chain shop in Japan. I feel proud that Formosa Chang can entertain overseas customers satisfactorily and win praise!"

Due to the previous pleasurable experience, mystery shopper $\mathrm{H}$ decided to treat his customers to food at the case-studied corporation and was willing to introduce his pleasurable experience to his relatives, friends and 
customers. The importance of improving the relations between consumers and the case-studied corporation is clearly shown in this situation, which indirectly increases the enterprise's turnover and enhances business performance.

\subsubsection{Value in Use}

As most restaurants of the case-studied corporation are located in the downtown area of the city, the inconvenience of parking has brought a lot of customer complaints. Therefore, the case-studied corporation organized "reception ambassadors", who were responsible for informing the door staff of the number of customers before they arrived and arranging seats in advance. More importantly, they helped customers by watching their car or car parking so that customers could dine at ease.

Mystery shopper F: "As Formosa Chang provides the service of looking after the car, I often call my friends to come and dine here. We don't have to worry about parking. This is the best service for me and my friends."

The reason for mystery shopper $\mathrm{F}$ calling friends to dine in the case-studied restaurant is quite simple; no parking problems. Reception ambassadors provide the highest degree of added value, which goes beyond customers' expectations and improves their experience quality in the restaurant. This is consistent with Palmer (2010) and Ma et al. (2011) argument.

\subsubsection{Relationship Outcome}

The purpose of founding the case-studied corporation was specified as "creating a happy life for partners, manufacturers, shareholders and customers by means of a bowl of braised pork on rice."

Mystery shopper E: "Because of the economic recession in 2009, I was fired without any warning. I faced financial pressure suddenly and wanted to end my life. Then, I passed Formosa Chang and decided to have a meal before killing myself. But when I entered, I had no appetite at all. A staff member about 50 years old saw me and offered me a bowl of hot soup and talked to me, which made me feel the warmth of this world. Then I gave up that terrible idea. To show my gratitude to this staff member, I often come back to consume in this restaurant so as to express my thanks."

Due to the case-studied corporation's sincere attitude towards mystery shopper E, which was like the care from one's family, the customer was willing to keep consuming in the restaurant, going back to the familiar place and experiencing the feeling of being cared for. Therefore, if a customer's experience is unforgettable enough, it will form a pleasurable motivation for him to keep consuming with a corporation. This is also consistent with social exchange theory.

\subsection{Business Performance}

As far as business performance is concerned, mystery shopper experience activity is clearly defined as a working guide for staff. The case-studied corporation promoted the willingness of its staff to learn via the methods of travel rewards and performance bonuses, encouraging staff to actively make suggestions on how to improve service processes and how to create new products.

The general manager said: "In early 2012, a total of 74 specific suggestions from different departments of the corporation were collected. Staff voluntarily made improvement suggestions, which were executed respectively under the inspection of the vice president of the corporation."

With regard to business performance, the created products being presented to the public were 7 pieces, 9 pieces, and 12 pieces from 2009 to 2011, while the development time was reduced to 1.2 months, 0.9 month and 0.7 month, respectively. From the aspect of financial performance, the case-studied corporation introduced mystery shopper activity in 2008, following which the average rate for its turnover growth reached $23.86 \%$ within three years, which was the rapidest speed over those years. The profit growth rate realized 32.28\%, 95.65\%, and $26.66 \%$ from 2009 to 2011, respectively, with an annual growth rate of over 20\%. Consequently, business performance was apparently improved through the practice of mystery shopper activity.

\section{Conclusions and Managerial Implications}

The present study provided a research approach to improve customer experience quality in Chinese restaurants frequented by Chinese people. The purpose was to search the customer information from the practice of mystery shoppers in a case study in order to assist Chinese restaurants to improve customer experience quality and enhance business performance. The key to a successful case study is to improve experience quality by employing complaining customers as mystery shoppers. These 86 customers acted as mystery shoppers after accepting suggestions from the corporation. This strategy had been a successful customer experience. The re-experience of the customers who became mystery shoppers not only included monitoring service quality, but also of improving 
personal experience quality so as to change previous experiences. Furthermore, the experience reports and suggestions provided by mystery shoppers would be highly valued by decision-makers, which would, in turn, bring closer relationship outcomes and improve experience quality, thus forming a virtuous cycle. The experience quality created by mystery shoppers of the case-studied corporation is unique and has reference value.

Meyer \& Schwager (2007) posed the following questions: (a) why was the management of customer experience neglected? (b) was it because there was no data that could prove whether it was driven by business or customers? (c) in addition, once there was a circulation of data, could the enterprise meet the requirements of customers? (d) what was the preference for the choice when conflicts occurred? These questions can be answered by the case study that aimed to improve customer experience quality. Mystery shoppers assigned by the enterprise in the case study had already undergone unpleasurable experiences and their information had been recorded in the database. They would feel the differences immediately between the current experience and the previous experience, when re-experiencing. The improved results could then bring wonderful customer experience quality for non-mystery-shoppers when they went to the restaurant. The use of external mystery shoppers may have certain drawbacks. For example, there may be high costs on one hand, and on the other hand there may be problems with the consistency and accuracy of evaluations (Beck et al., 2004). However, the employment of customers with unpleasurable experiences as mystery shoppers in the case study would not only reduce the cost, but also bring the advantage of external mystery shoppers into full play. This would be more just and objective than using internal employees; and the assessment results would be more suited to actual circumstances (McLuhan, 2010).

Turnover during the three years after the case-studied corporation introduced mystery shoppers saw an average increase of $23.86 \%$, being the fastest growing period over the previous years. The positive response from mystery shoppers $\mathrm{A}, \mathrm{B}, \mathrm{C}$, and $\mathrm{G}$ and the experiences provided by mystery shoppers $\mathrm{E}, \mathrm{F}$, and $\mathrm{H}$ formed continuous re-purchases. The above results were consistent with the fact that the improvement in experience quality led to customer loyalty and word of mouth, which was directly connected to an enterprises' ability to make profits. Furthermore, usage value played a role in regulating customer experience quality and relationship outcomes. In the case study, reception ambassadors freed customer $\mathrm{F}$ from parking troubles, brought customer $\mathrm{F}$ good experience quality, and reinforced the relations between customers and the case-studied corporation, thus supporting Palmer's (2010) viewpoints.

There are two implications from the management practice of the study. First, this study filled the gap from previous studies on customer experience quality in China's catering industry, and offered a way to use mystery shoppers to improve the customer's experience quality. As for the selection of mystery shoppers, appropriate customers can be screened by a database of customer complaints. Second, there should be a matching method for mystery shoppers' actions. The case study provided information on "Mystery Shoppers Going Home" and a "Symposium on Mystery Shoppers' Focuses" as a reference. Furthermore, senior executives, including the president and general managers, actively participated in and used an ISO quality management program for a sustainable improvement in management. Their actions also played a decisive role in mystery shoppers' willingness to support the enhancement of experience quality.

\section{References}

Beck, J., Lalopa, J., \& Hall, J. (2004). Insuring Quality Service. Journal of Human Resources in Hospitality \& Tourism, 2(2), 41-56. http://dx.doi.org/10.1300/J171v02n02_03

Berry, L. L., \& Carbone, L. P. (2007). Build Loyalty Through Experience Management. Quality Progress, 40(9), $26-32$.

Berry, L. L., Carbone, L. P., \& Haeckel, S. H. (2002). Managing the Total Customer Experience. MIT Sloan Management Review, 43(3), 85-89. http://dx.doi.org/10.1225/SMR082

Erstad, M. (1998). Mystery shopping programs and human resource management. International Journal of Contemporary Hospitality Management, 10(1), 34-44. http://dx.doi.org/10.1108/09596119810199318

Finn, A., \& Kayande', U. (1999). Unmasking a phantom: A psychometric assessment of mystery shopping, Journal of Retailing, 75(2), 195-217. http://dx.doi.org/10.1016/S0022-4359(99)00004-4

Gentile, C., Spiller, N., \& Noci, G. (2007). How to Sustain the Customer Experience: An Overview of Experience Components that Co-create Value With the Customer. European Management Journal, 25(5), 395-410. http://dx.doi.org/10.1016/j.emj.2007.08.005

Grewal, D., Levy, M., \& Kumarc, V. (2009). Customer Experience Management in Retailing: An Organizing 
Framework. Journal of Retailing, 85(1), 1-14. http://dx.doi.org/10.1016/j.jretai.2009.01.001

Heung, V. C. S., \& Ngai, E. W. T. (2008). The Mediating Effects of Perceived Value and Customer Satisfaction on Customer Loyalty in the Chinese Restaurant Setting. Journal of Quality Assurance in Hospitality \& Tourism, 9(2), 85-107. http://dx.doi.org/10.1080/15280080802235441

Johnston, R. (1999). Service transaction analysis: assessing and improving the customer's experience. Managing Service Quality, 9(2), 102-109. http://dx.doi.org/10.1108/09604529910257876

Johnston, R., \& Kong, X. (2011). The customer experience: a road-map for improvement. Managing Service Quality, 21(1), 5-24. http://dx.doi.org/10.1108/09604521111100225

Lemke, F., Clark, M., \& Wilson, H. (2010). Customer experience quality: an exploration in business and consumer contexts using repertory grid technique. Journal of the Academy of Marketing Science, 39(6), 846-869. http://dx.doi.org/10.1007/s11747-010-0219-0

Ma, J. E., Qu, H., Njite, D., \& Chen, Su. (2011). Western and Asian Customers' Perception Towards Chinese Restaurants in the United States. Journal of Quality Assurance in Hospitality \& Tourism, 12(2), 121-139. http://dx.doi.org/10.1080/1528008X.2011.541818

Maklan, S., \& Klaus, P. (2011). Customer Experience: Are We Measuring the Right Things. International Journal of Market Research, 53(6), 23-29.

McLuhan, R. (2010). Genuine buy-in is key to mystery shopping. Marketing, 36.

Meyer, C., \& Schwager, A. (2007). Understanding customer experience. Harvard Business Review, 85(2), $116-126$.

Nunes, P. F., \& Cespedes, F. V. (2003). The customer has escaped. Harvard Business Review, 81(1), 96-105.

Palmer, A. (2010). Customer experience management: a critical review of an emerging idea. Journal of Services Marketing, 24(3), 196-208. http://dx.doi.org/10.1108/08876041011040604

Rowley, J. (1999). Measuring total customer experience in museums. International Journal of Contemporary Hospitality Management, 11(6), 303-308. http://dx.doi.org/10.1108/09596119910281801

Ryu, K., Lee, H.R., Kim, W. G. (2012). The influence of the quality of the physical environment, food, and service on restaurant image, customer perceived value, customer satisfaction, and behavioral intentions. International Journal of Contemporary Hospitality Management, 24(2), 200-223. http://dx.doi.org/10.1108/09596111211206141

Simon, A., \& Petnji Yaya, L. H. (2012). Improving Innovation and Customer Satisfaction through Systems Integration. Industrial Management \& Data Systems, 112(7), 1026-1043. http://dx.doi.org/10.1108/02635571211255005

Teixeira, J., Patrício, L., Nunes, N. J., Nóbrega, L., Fisk, R. P., \& Constantine, L. (2012). Customer experience modeling: from customer experience to service design. Journal of Service Management, 23(3), 362-376. http://dx.doi.org/10.1108/09564231211248453

Wang, Y., \& Mattila, A. (2008, July). The role of culture in customer references for service failure explanations. Presented at the 2008 ICHRIE Conference, Atlanta, GA.

Wiele, A., Hesselink, M. G., \& Iwaarden, J. D. (2005). Mystery shopping: A tool to develop insight into customer service provision. Total Quality Management \& Business Excellence, 16(4), 529-541. http://dx.doi.org/10.1080/14783360500078433

Wilson, A. M. (1998). The role of mystery shopping in the measurement of service performance. Managing Service Quality, 8(6), 414-420. http://dx.doi.org/10.1108/09604529810235123

Wilson, A. M. (2001). Mystery Shopping: Using Deception to Measure Service Performance. Psychology \&Marketing, 18(7), 721-734. http://dx.doi.org/10.1002/mar.1027

Yin, R. K. (2008). Case Study Research: Design and Methods (4th ed.). Sage Publications.

\section{Copyrights}

Copyright for this article is retained by the author(s), with first publication rights granted to the journal.

This is an open-access article distributed under the terms and conditions of the Creative Commons Attribution license (http://creativecommons.org/licenses/by/3.0/). 